\title{
A Constrained Non-Linear Model Predictive Controller for the Rotor Flux-Oriented Control of an Induction Motor Drive
}

\author{
Fabiano C. Rosa ${ }^{1,2, *,+}$ (D) and Edson Bim ${ }^{1, *,+}$ \\ 1 Faculty of Electrical and Computer Engineering, State University of Campinas, \\ Campinas 13083-852, São Paulo, Brazil \\ 2 Federal Institute of Education, Science and Technology of São Paulo (IFSP), Campus Suzano, \\ Suzano 08673-010, São Paulo, Brazil \\ * Correspondence: fabiano.camargo.rosa@ifsp.edu.br (F.C.R.); bim@unicamp.br (E.B.) \\ + These authors contributed equally to this work.
}

Received: 12 May 2020; Accepted: 9 June 2020; Published: 31 July 2020

check for updates

\begin{abstract}
Predictive controllers have been extensively studied and applied to electrical drives, mainly because they provide fast dynamic responses and are suitable for multi-variable control and non-linear systems. Many approaches perform the prediction and optimization process on-line, which requires a high computational capacity for fast dynamics, such as, for example, the control of AC electric motors. Due to the complexity of embedding constraints in controller design, which demands a high computational capacity to solve the optimization problem, off-line approaches are one of the choices to overcome this problem. However, these strategies do not deal with the inherent constraints of the drive system, which significantly simplifies the design of the controller. This paper proposes a non-linear and multi-variable predictive controller to control the speed and rotor flux of an induction motor, where the constraints are treated after the controller design. Besides dealing with the constraints of the electric drive system, our proposal allows increasing the stability of the system when the model does not incorporate disturbances and when parameter incompatibilities occur. Several computer simulations and experimental tests were performed to evaluate the behavior of the proposed controller, showing good performance to track the controlled variables under normal operating conditions, under load disturbances, parametric incompatibility, and at a very low rotor speed.
\end{abstract}

Keywords: AC motor drives; induction motors; non-linear systems; predictive control; robustness

\section{Introduction}

Induction motors (IM) are multi-variable and non-linear systems subject to parametric variations and external disturbances, requiring, therefore, a high performance control system. Therefore, advanced control techniques, such as sliding mode control [1,2], fuzzy logic [3], artificial neural networks [4-6], and model predictive controllers (MPC) [7-9] have been applied to electric drives.

Model-based predictive control is a family of controllers whose formulation is suitable for non-linear and multi-variable systems and allows natural handling constraints on the input or output variables [10,11]. Besides, its design is easily implemented and results in faster dynamic responses to command signals, when compared to other controllers [12,13]. Two non-linear design techniques have been widely employed for the power converter and drive applications: the Continuous Control Set-Non-linear Model Predictive Control (CCS-NMPC) and the Finite Control Set-Non-linear Model Predictive Control (FCS-NMPC) [14,15]. In the case of our present work, the focus is on CCS-NMPC, 
which calculates a continuous control signal and uses a modulator to generate the desired output voltage in the power converter [16].

Unlike FCS-NMPC, CCS-NMPC establishes a fixed switching frequency that concentrates the harmonic spectrum of the current around the switching frequency [13] and, thereby, simplifies the design and reduces the cost of the harmonic filter.

Many model predictive approaches perform the prediction and optimization process iteratively on-line to obtain the optimal control action [17], requiring high capacity processors, mainly if long prediction horizon or small sampling time are used [18]. On the other hand, some approaches make use of analytical methods with low computational load to optimize the cost function of CCS-NMPC. However, if the constraints are considered as optimization criteria, these algorithms are computationally intensive and very complex to be used in systems whose dynamics is extremely fast, such as electric drives [19], only the unconstrained CCS-NMPC being considered in these cases.

In an attempt to ensure the robust operation of the drive system, i.e., keep the motor current in its boundary values, some strategies decrease the gain values of the unconstrained CCS-NMPC for reducing its control effort, trying to keep the electric current within the limits, as suggested by [20]. One of the main disadvantages of that strategy is the potential emergence of high frequency oscillations and, consequently, instabilities, such as [20]. Another standard strategy applied to resolve this problem appeared in [21-24], where second-order filters were employed to smooth the reference signal. The purpose of using the second-order filter was to slow down the reference signal, thus reducing the motor stator current. The disadvantage of employing filters is that they provide slow responses without ensuring, under some conditions-such as full load motor starting, eventual overload, and speed reversion-that the electrical current does not exceed the acceptable limits for convenient operation.

With a focus on keeping the state and control variables within the desired limits, some approaches design the controller in a cascade structure, allowing the use of simple blocks to saturate the state and control variables, as proposed in [25] for restricting the $q$-axis current of a PMSM. The disadvantage of this approach is that it requires two CCS-NMPC to be designed, where the outer loop controller is designed to regulate the rotor angular speed and the inner loop controller regulates the current stator components of the $d q$-axis. If a similar approach is chosen to control the angular speed and the rotor flux of an induction motor, the extra control loop would increase the design complexity of the CCS-NMPC and the number of parameters to be defined as well-four instead of two. Besides the aforementioned drawbacks, generally, the outer loop of the cascade controllers is designed to have a relatively slow dynamics response in comparison to the inner loop and, therefore, ensure a stable operation. Thereby, the development control techniques based on the non-cascade structure have been used [26]. In this approach, the predicted speed tracking error is directly used to determine the required voltage command without the need for a cascaded control scheme, however requiring exact knowledge of the system model to guarantee an accurate prediction of the system behavior, while the PMSM is usually subjected to model uncertainties and external disturbances such as the load torque.

Thereby, another critical aspect of the model predictive control techniques is the requirement of precise mathematical models to provide satisfactory performance $[27,28]$, which requires the knowledge of external disturbances that are usually determined by observers [29]. The problem with using observers is that generally, their algorithms are computationally heavy, making the implementation of predictive controllers in systems with low or medium computational capacity even more challenging.

An integral control action is added to the control law of CCS-NMPC to control the rotation of the PMSM [20] to overcome problems arising from uncertainties and non-modeled disturbances; however, this strategy demonstrated a high immunity to non-modeled disturbances and the parametric motor variations. The cost function is based on the predicted integral action of the tracking error, and the controller is developed under the assumption that the system is free from any disturbance and mismatched parameters. Besides, due to the windup phenomenon, the use of the integral control action has the potential to deteriorate the dynamic response with oscillating behavior or, in the worst 
case, make the system unstable. A candidate strategy to address the constraint problems of CCS-NMPC appeared in [30], where the constraints of the drive system were handled after the synthesis of a state feedback controller applied to control the angular speed of PMSM. Basically, it makes use of the PMSM mathematical model to determine at each sample time the maximum allowable value of the system input that keeps the state variables within the desired limit. If the input value exceeds this limit, it is saturated using a simple saturation block. The effectiveness of this strategy ensures that the values of the constrained variables remain within the specified range, and its low computational cost constitutes its main advantage.

This paper proposes a simple strategy to restrict the state and the control variables of the induction motor in the case of a non-cascade and non-linear multi-variable CCS-NMPC with integral action and such that one can control the rotor angular speed and rotor flux of the induction motor. Unlike the CCS-NMPC approaches found in the literature, the approach proposed in this work is able to address the restrictions of the motor and the power converter, e.g., current and voltage, in cases where CCS-NMPC is designed on the direct structure. Therefore, the design of the controller is simplified, and the operational safety of the system is guaranteed. Furthermore, the proposed methodology to incorporate the anti-windup control action into the CCS-NMPC controller provides fast dynamic responses and improves the stability of the system, even if severe parametric incompatibilities occur.

\section{Three Phase Induction Motor Model}

\subsection{Rotor Flux Control}

In the Rotor Flux-Oriented Control (RFOC) of an induction machine, the $q$-axis rotor flux is zero, i.e., $\psi_{q r}=0$, and so, the rotor flux equation is:

$$
\frac{d \psi_{r}}{d t}+\frac{1}{\tau_{r}} \psi_{r}=\frac{L_{m}}{\tau_{r}} i_{d s}
$$

where the time constant $\tau_{r}=L_{r} / r_{r}$ is the ratio between the rotor self-inductance and the rotor resistance; $L_{m}$ denotes the magnetizing inductance; $\psi_{r}$ is the $d$-axis rotor flux; and $i_{d s}$ is the $d$-axis stator current.

In our case, the rotor flux position, $\theta_{r}$, is determined by:

$$
\theta_{r}=\int\left(\omega_{r}+\omega_{s l}\right) d t
$$

in which $\omega_{r}$ is the angular reference speed of the rotor in electrical radians per second and $\omega_{s l}$ is the slip speed of the rotor flux, whose value is given by:

$$
\omega_{s l}=\frac{1}{\tau_{r}^{*}} \frac{i_{q s}}{i_{d s}}
$$

where $\tau_{r}^{*}$ is the reference value of the rotor constant and $i_{q s}$ is the $q$-axis stator current.

One observes, by inspection of Equations (2) and (3), the dependence of the rotor flux position on the rotor time constant, i.e., it depends on the resistance $r_{r}$ and the self-inductance $L_{r}$. In practical applications, these parameters vary with temperature and slip frequency, and so, depending on the kind of controller used, it may be mandatory to update their values.

The other equations for the rotor flux oriented control are:

$$
\begin{aligned}
& \frac{d i_{d s}}{d t}=-m i_{d s}+\omega_{s} i_{q s}+\frac{L m}{\sigma L s L r \tau_{r}} \psi_{r}+\frac{1}{\sigma L_{s}} u_{d s} \\
& \frac{d i_{q s}}{d t}=-\omega_{s} i_{d s}-m i_{q s}-\frac{L m}{\sigma L s L r} \omega_{r} \psi_{r}+\frac{1}{\sigma L_{s}} u_{q s} \\
& \frac{d \omega_{r}}{d t}=z \psi_{r} i_{q s}-\frac{b}{J_{t}} \omega_{r}-\frac{p}{J_{t}} \Gamma
\end{aligned}
$$


in which $u_{d s}$ and $u_{q s}$ are the $d$-axis and $q$-axis components of the stator voltage, $r_{s}$ and $r_{r}$ are the stator and rotor resistances per phase, $L_{s}$ and $L_{r}$ are the stator and rotor self-inductances per phase, respectively, $J_{t}$ is the total inertial moment, $b$ is the viscous friction, $p$ is the number of pole pairs, $\omega_{s}$ is the spatial synchronous speed of the rotor flux, and $\Gamma$ is the load torque disturbance. We still have in these latter equations,

$$
m=\frac{1}{L_{s} \sigma}\left(r_{s}+r_{r} \frac{L m^{2}}{L r^{2}}\right) \quad z=\frac{3}{2} \frac{p}{J_{t}} \frac{L_{m}}{L_{r}} \quad \sigma=1-\frac{L m^{2}}{L s L r}
$$

\subsection{Representation in the Continuous State-Space Model}

The control of induction motors is a multi-variable non-linear control system described by $m$ inputs, $u_{1} u_{2} \ldots u_{m}$, and $p$ outputs, $y_{1} y_{2} \ldots y_{p}$, whose representation in state-space form is given by the set of equations:

$$
\left\{\begin{array}{l}
\dot{x}(t)=f(x)+g_{1} u(t)+g_{2} d(t) \\
y(t)=h(x)
\end{array}\right.
$$

In RFOC, the state vector, $x$, the input vector, $u$, and the disturbance vector, $d$, are:

$$
x=\left[\begin{array}{c}
i_{d s} \\
i_{q s} \\
\psi_{r} \\
\omega_{r}
\end{array}\right] \quad u=\left[\begin{array}{l}
u_{d s} \\
u_{q s}
\end{array}\right] \quad d=\left[\begin{array}{l}
0 \\
0 \\
0 \\
\Gamma
\end{array}\right]
$$

The output vector is:

$$
y(t)=\left[\begin{array}{l}
h_{1}(x) \\
h_{2}(x)
\end{array}\right]=\left[\begin{array}{l}
\psi_{r} \\
\omega_{r}
\end{array}\right]
$$

The vector $f(x)$ in (5) is:

$$
f(x)=\left[\begin{array}{l}
f_{1}(x) \\
f_{2}(x) \\
f_{3}(x) \\
f_{4}(x)
\end{array}\right]=\left[\begin{array}{c}
-m i_{d s}+\omega_{s} i_{q s}+\frac{L m}{\sigma L s L r} \psi_{r} \\
-\omega_{s} i_{d s}-m i_{q s}-\frac{L m}{\sigma L s L r} \omega_{r} \psi_{r} \\
\frac{L m}{\tau_{r}} i_{d s}-\frac{1}{\tau_{r}} \psi_{r} \\
z \psi_{r} i_{q s}-\frac{b}{J_{t}} \omega_{r}
\end{array}\right]
$$

The matrices $g_{1}$ and $g_{2}$ are:

$$
g_{1}=\left[\begin{array}{cc}
\frac{1}{\sigma L s} & 0 \\
0 & \frac{1}{\sigma L s} \\
0 & 0 \\
0 & 0
\end{array}\right] \quad g_{2}=\left[\begin{array}{cccc}
0 & 0 & 0 & 0 \\
0 & 0 & 0 & 0 \\
0 & 0 & 0 & 0 \\
0 & 0 & 0 & \frac{-P}{J_{t}}
\end{array}\right]
$$

In terms of control, it is important to note in these equations that $f(x), g(x)$, and $h(x)$ are smooth vector fields, allowing, then, their respective linearization.

\section{Formulation of the CCS-NMPC Algorithm}

Although CCS-NMPC is well established in the literature and experimentally validated for PMSM, it has hardly been applied to induction motors. The objective of our multi-variable CCS-NMPC controller is to find the optimal inputs such that the expected plant outputs follow the reference. The CCS-NMPC controller concept is based on the moving horizon time frame principle where the basic idea is that at each time $t$, within a moving horizon time frame located at time $t$, find the optimal control action, $u(t)$, to bring the future plant outputs, $\hat{y}_{i}(t+\tau)$, for your references, $\hat{y}_{r i}(t+\tau)$. Just to distinguish from real variables, hatted variables are the predicted variables defined in the moving horizon time frame. When the dynamics of the controlled variables are very different from each 
other, the control effort has to be set independently for each controlled variable [20] to attain high performance. Based on this strategy and the adjustment procedure suggested in [31], we propose the following cost function for the rotor flux-oriented control of a three phase induction motor:

$$
J=\frac{1}{2} \int_{0}^{T_{p 1}} \hat{I}_{1}(t+\tau)^{2} d \tau+\frac{1}{2} \int_{0}^{T_{p 2}} \hat{I}_{2}(t+\tau)^{2} d \tau
$$

where $\hat{I}_{1}(t+\tau)$ and $\hat{I}_{2}(t+\tau)$ are the integral of the errors in the moving prediction horizon, $T_{p i}$, and $\tau$ is a time constant, with $0 \leq \tau \leq T_{p i}$ for $\forall T_{p i}$. Thus, the integral terms in the cost function can be approximated by Taylor series whose order is $\left(\rho_{i}+1\right)$, i.e.,

$$
\hat{I}_{i}(t+\tau)=I_{i}(t)+\tau e_{i}(t)+\frac{\tau^{2}}{2 !} \dot{e}_{i}(t)+\cdots+\frac{\tau^{\rho_{i}+1}}{\left(\rho_{i}+1\right) !} e_{i}^{\rho_{i}}(t), \quad i=1,2
$$

$\rho_{i}$ is the relative degree of the $i^{\text {th }}$ output and represents the number of times that were needed to differentiate the respective output $i$ until obtaining an explicit relation between the output and input [32].

In our case, $\rho_{1}=2$ and $\rho_{2}=2$, defining the total relative degree of the system, $\rho=\rho_{1}+\rho_{2}=4$. As $\rho$ is equal to the order of the system, the input-output map can be fully linearized, and the system does not have zero dynamics [33].

The measured error for the $i^{\text {th }}$ controlled variable is:

$$
e_{i}(t)=y_{r i}(t)-y_{i}(t), \quad i=1,2
$$

where $y_{r i}$ is the reference signal and $y_{i}$ is the measured output. The integral of the error is then:

$$
I_{i}(t)=\int_{0}^{t} e_{i}(\tau) d \tau, \quad i=1,2
$$

In the case of ignoring the effects of external disturbances, the output derivatives required to calculate the derivatives in (11) are computed as follows:

$$
y_{i}^{(j)}=\mathcal{L}_{f}^{j} h_{i}(x)+\mathcal{L}_{g 1} \mathcal{L}_{f}^{(j-1)} h_{i}(x) u(t), \quad j=1 \ldots \rho_{i}
$$

where $j$ denotes the derivative order and $\mathcal{L}_{f} h_{i}(x)$ is the Lie derivative of $h_{i}(x)$ along the vector field $f(x)$ :

$$
\mathcal{L}_{f} h_{i}(x)=\frac{\partial h_{i}(x)}{\partial x} f(x)
$$

and the $j^{\text {th }}$ Lie derivative can be computed interactively, as follows:

$$
\mathcal{L}_{f}^{j} h_{i}(x)=\mathcal{L}_{f}\left(\mathcal{L}_{f}^{j-1} h_{i}(x)\right)
$$

and:

$$
\mathcal{L}_{g_{1}} \mathcal{L}_{f} h_{i}(x)=\frac{\partial \mathcal{L}_{f} h_{i}(x)}{\partial x} g_{1}
$$

Thus, the prediction expression (11), written in matrix form, becomes:

$$
\hat{I}_{i}(t+\tau)=\Lambda_{i} M_{i}-\Lambda_{i} C_{i}
$$

where the matrix $\Lambda_{i}$ contains the coefficients of the Taylor series:

$$
\Lambda_{i}=\left[\begin{array}{lll}
1 & \tau & \frac{\tau^{2}}{2 !} \cdots \frac{\tau^{\left(\rho_{i}+1\right)}}{\left(\rho_{i}+1\right) !}
\end{array}\right]
$$


and:

$$
M_{i}=\left[\begin{array}{c}
I_{i} \\
y_{r i}-h_{i} \\
\dot{y}_{r i}-\mathcal{L}_{f} h_{i} \\
\ddot{y}_{r i}-\mathcal{L}_{f}^{2} h_{i} \\
\vdots \\
y_{r i}^{\left(\rho_{i}\right)}-\mathcal{L}_{f}^{\rho_{i}} h_{i}
\end{array}\right] \quad C_{i}=\left[\begin{array}{c}
0 \\
0 \\
0 \\
0 \\
\vdots \\
\mathcal{L}_{g_{1}} \mathcal{L}_{f}^{\rho_{i}-1} h_{i} u(t)
\end{array}\right]
$$

As pointed out before, the relative degrees of the outputs, $y_{1}$ and $y_{2}$, are $\rho_{1}=2$ e $\rho_{2}=2$, respectively, and so, we can write:

$$
\begin{gathered}
\Lambda_{1}=\Lambda_{2}=\left[\begin{array}{lll}
1 \tau & \frac{\tau^{2}}{2 !} & \tau^{3} \\
3 !
\end{array}\right] \\
M_{1}=\left[\begin{array}{c}
I_{1} \\
y_{r 1}-h_{1} \\
\dot{y}_{r 1}-\mathcal{L}_{f} h_{1} \\
\ddot{y}_{r 1}-\mathcal{L}_{f}^{2} h_{1}
\end{array}\right] \quad M_{2}=\left[\begin{array}{c}
I_{2} \\
y_{r 2}-h_{2} \\
\dot{y}_{r 2}-\mathcal{L}_{f} h_{2} \\
\ddot{y}_{r 2}-\mathcal{L}_{f}^{2} h_{2}
\end{array}\right] \\
C_{1}=\left[\begin{array}{llll}
0 & 0 & 0 & \mathcal{L}_{g_{1}} \mathcal{L}_{f} h_{1} u(t)
\end{array}\right]^{t} \quad C_{2}=\left[\begin{array}{llll}
0 & 0 & 0 & \mathcal{L}_{g_{1}} \mathcal{L}_{f} h_{2} u(t)
\end{array}\right]^{t}
\end{gathered}
$$

The condition for the control law to be optimal is given by:

$$
\frac{d J}{d u}=0
$$

that applied to (10) yields the following optimal control law:

$$
u(t)=\left[\begin{array}{l}
u_{d s}(t) \\
u_{q s}(t)
\end{array}\right]=G_{1}^{-1}(x)\left[\begin{array}{l}
K_{1} M_{1} \\
K_{2} M_{2}
\end{array}\right]
$$

with:

$$
G_{1}=\left[\begin{array}{c}
\mathcal{L}_{g_{1}} \mathcal{L}_{f} h_{1} \\
\mathcal{L}_{g_{1}} \mathcal{L}_{f} h_{2}
\end{array}\right]=\left[\begin{array}{cc}
\frac{L m}{\tau_{r}} \frac{1}{\sigma L_{s}} & 0 \\
0 & z \psi_{r} \frac{1}{\sigma L_{s}}
\end{array}\right]
$$

The vectors $K_{1}$ and $K_{2}$ contain the controller gains and are determined following the procedure described in [21], i.e.,

$$
K_{1}=\left[\frac{21}{2 T_{p 1}^{3}} \frac{42}{5 T_{p 1}^{2}} \frac{7}{2 T_{p 1}} 1\right] \quad K_{2}=\left[\frac{21}{2 T_{p 2}^{3}} \frac{42}{5 T_{p 2}^{2}} \frac{7}{2 T_{p 2}} 1\right]
$$

Note that the predictive periods $T_{p 1}$ and $T_{p 2}$ are the only parameters that must be tuned to achieve the desired performance. Long predictive periods produce slow dynamic responses. However, if these periods are too long, high frequencies may arise, or the system even becomes unstable. On the other hand, faster dynamic responses occur for small predictive periods; however, if it is too small, the controller behaves as having a high gain controller, then amplifying the measurement noise.

\section{Constraining the State and Control Variables}

The primary purpose of limiting the values of the state and control variables is to ensure the safe operation of a drive system. Moreover, restricted controllers attain a fast dynamic response and superior steady-state behavior for enabling the use of high gains without exceeding the limits of safe operation. In our study, restrictions are added after the CCS-NMPC controller synthesis, ignoring, therefore, in this step, the limits of the state and control variables. The general idea that characterizes this approach is to employ the mathematical model of the IMto determine the limits 
of the control variables that guarantee the future values of the state variables remain within the appropriate pre-established ranges. It is usual to restrict the $q$-axis stator current $i_{q s}$ to maintain the electromechanical torque at the rated motor value and the $d$-axis and $q$-axis components of the stator voltages, $u_{d s}$ and $u_{q s}$, because one can deal with the restrictions of the motor and the power converter as well. The future state of the $q$-axis stator current, $i_{q s}(k+1)$, is determined by employing the mathematical model described in (5), after its discretization by the Euler method, as follows:

$$
i_{q s}(k+1)=i_{q s}(k)+T_{s}\left[f_{2}(x)+\frac{1}{\sigma L_{s}} u_{q s}(k)\right]
$$

Denoting the maximum value of $i_{q s}(k+1)$ by $i_{q s, H}$ and its minimum value by $i_{q s, L}$, the substitution of these values in this equation generates the boundary values of the $q$-axis stator voltage that maintain the $q$-axis current within a specific range: $u_{q s, H}(k)$ is the maximum acceptable value, and $u_{q s, L}(k)$ is its minimum:

$$
\begin{aligned}
& u_{q s, H}(k)=\sigma L_{s}\left[\frac{1}{T_{s}}\left(i_{q s, H}-i_{q s}(k)\right)-f_{2}(x)\right] \\
& u_{q s, L}(k)=\sigma L_{s}\left[\frac{1}{T_{s}}\left(i_{q s, L}-i_{q s}(k)\right)-f_{2}(x)\right]
\end{aligned}
$$

The values of $u_{q s, H}(k)$ and $u_{q s, L}(k)$ establish the points of saturation of the control variable $u_{q s}$ : when it reaches its high or low value, the control signal saturates, characterizing, therefore, an actuator, where:

$$
u_{q s}^{*}=\left\{\begin{array}{l}
u_{q s, H}(k), \quad \text { if } u_{q s} \geq u_{q s, H} \\
u_{q s, L}(k), \quad \text { if } u_{q s} \leq u_{q s, L} \\
u_{q s}(t), \quad \text { otherwise }
\end{array}\right.
$$

The employment of saturation functions generates the phenomenon known as a windup, whose existence becomes the controller being unable to respond promptly when the saturation points are reached, and this may even cause instabilities of the system [34]. The classical tracking back-calculation method was adopted, according to [35], to avoid the windup phenomenon. This anti-windup action was added to CCS-NMPC and modified the $M_{2}$ matrix, given in (22), as follows:

$$
\bar{M}_{2}=\left[\begin{array}{c}
I_{2}-\frac{k_{\text {awp }} u_{a w p}}{21 /\left(2 T_{2}^{3}\right)} \\
y_{r 2}-h_{2} \\
\dot{y}_{r 2}-\mathcal{L}_{f} h_{2} \\
\ddot{y}_{r 2}-\mathcal{L}_{f}^{2} h_{2}
\end{array}\right]
$$

where $k_{\text {awp }}$ is the anti-windup coefficient, which is empirically adjusted, and $u_{\text {aww }}$ is the difference between the unsaturated and saturated values of the control action $u_{q s}$, i.e.,

$$
u_{a w p}=u_{q s}^{*}-u_{q s}
$$

The control variable $u_{d s}$ is saturated and expressed as:

$$
u_{d s}^{*}=\left\{\begin{array}{l}
u_{d s, H}(k), \quad \text { if } u_{d s} \geq u_{d s, H} \\
u_{d s, L}(k), \quad \text { if } u_{d s} \leq u_{d s, L} \\
u_{d s}(t), \quad \text { otherwise }
\end{array}\right.
$$

where $u_{d s, L}$ and $u_{d s, H}$ define the high and low voltage limits of the direct axis stator.

\section{Rotor Flux Estimation}

In this application, the information of the magnitude of the rotor flux is necessary to perform the rotor flux control. The use of discretized models is more suitable in practical implementations, 
and therefore, the discrete time model that performs the rotor flux estimation is obtained by applying Euler's discretization method in Equation (1):

$$
\psi_{r}(k)=\left(1-\frac{T_{s}}{\tau_{r}}\right) \psi_{r}(k-1)+\frac{L_{m}}{\tau_{r}} T_{s} i_{d s}
$$

where $T_{S}$ is the sampling time and $k$ denotes the present sampling instant.

The block diagram of the constrained CCS-NMPC is shown in Figure 1. Observe that each reference signal, i.e., the rotor flux reference, $\psi_{r}^{*}$, and speed reference, $\omega_{r}^{*}$, are smoothed by a second-order filter, making Taylor's series (11) possible for a discontinuous reference.

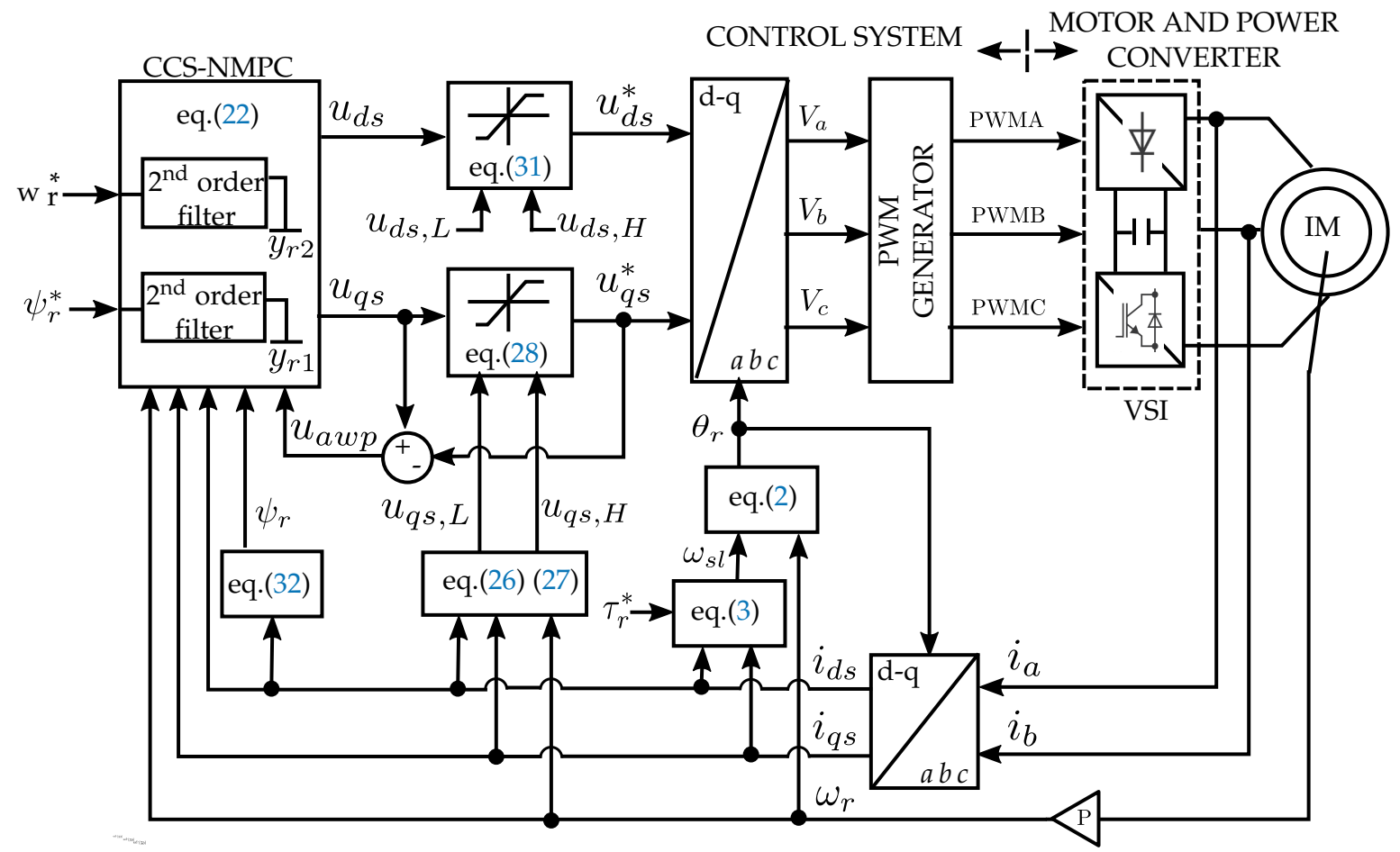

Figure 1. Block diagram of the restricted Continuous Control Set-Non-linear Model Predictive Control (CCS-NMPC). VSI, Voltage Source Inverter; $a b c$ represent three-phase quantities.

\section{Computer Simulation and Experimental Results}

The motor was subjected to the conditions of free starting and sudden loading to check the performance of the proposed controller. For this, the capacity of the proposed CCS-NMPC in controlling the rotor speed and keeping the rotor flux-oriented was verified by computational simulation and experimental results, considering the variation of the parameters and the imposed electrical limits as well: $i_{q s, H}=5.5 \mathrm{~A}$ and $i_{q s, L}=-5.5 \mathrm{~A}$ and $u_{d s, H}=311 \mathrm{~V}$ and $u_{q s, L}=-311 \mathrm{~V}$. The predictive periods of $\psi_{r}$ and $\omega_{r}$ were $T_{p 1}=2 \mathrm{~ms}$ and $T_{p 2}=10 \mathrm{~ms}$, respectively. The natural frequency and damping coefficient for the second-order filter used for the constrained CCS-NMPC were $\omega_{n}=400 \mathrm{rad} \mathrm{s}^{-1}$ and $\zeta=1$, respectively. The rated data of the motor are in Appendix A.

\subsection{Computational Simulation}

The system behavior was initially analyzed in a computer environment with the aid of MATLAB ${ }^{\circledR}$ software. The controller and the induction motor models were discretized with a sampling frequency of $10 \mathrm{kHz}$ and $500 \mathrm{kHz}$, respectively. The Voltage Source Inverter (VSI) was simulated using the Simulink ${ }^{\circledR}$ VSI model. 


\subsubsection{A Comparative Study}

To compare the performance, the CCS-NMPC used to control permanent synchronous motors [20] was adapted to be applied to the control of induction motors-from now on called the standard CCS-NMPC - and thus to compare it with our proposed controller, hoping to improve the stability and dynamics of the response.

This study clearly revealed the stability problem of the standard CCS-NMPC (Figure 2) and the correction made by our approach (Figure 3). The analyses of Figure 2a,b showed high oscillations in the speed and rotor flux responses, respectively. It was also evident that the system became unstable after the motor underwent a sudden reversal of speed, at the instant $4 \mathrm{~s}$. Moreover, observe in Figure 2c that the $q$-axis current reached very high values that would damage the power converter and the motor. On the other hand, under the same conditions, our controller (Figure 3) remained stable and tracked the rotor angular speed reference (Figure $3 a$ ) and the rotor flux reference (Figure $3 b$ ) without exceeding the imposed $q$-axis stator current limits (Figure 3c).

\subsubsection{Analyses of the Proposed Controller}

The computational simulation results of a three phase induction motor controlled by the proposed CCS-NMPC are shown in Figure 4. From these results, one could make the following observations:

(a) The settling time of the speed during start-up was $263 \mathrm{~ms}$ and under speed reversion was $444 \mathrm{~ms}$, as can be seen in details in Figure 5a,b, respectively. Note also that for the load torque perturbation, shown in Figure $4 b$, the rotor speed did not change.

(b) The direct-axis rotor flux remained constant at its reference value, as was expected in a rotor flux orientation, despite the load changing, as shown in Figure 4c.

(c) During transient periods (Figure $4 \mathrm{~d}$ ), the $q$-axis stator current did not exceed its limits, given by $i_{q s, H}$ and $i_{q s, L}$.

(d) Note in Figure $4 \mathrm{e}$ that during the transient, the voltage $u_{q s}$ was limited by the boundary values $u_{q s, L}$ and $u_{q s, H}$ to ensure that the values of $i_{q s}$ were within the allowed range.
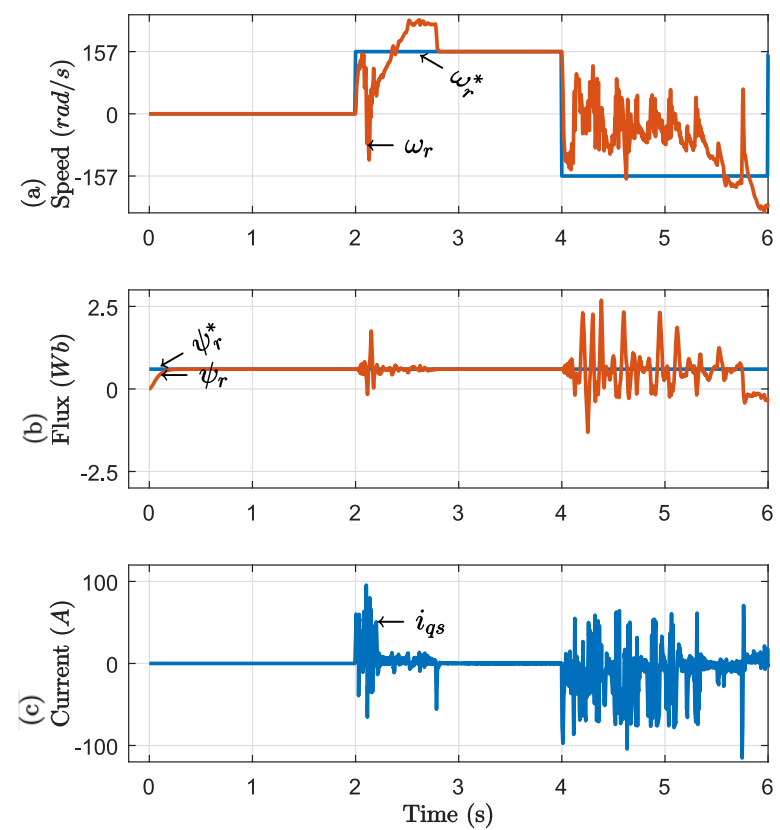

Figure 2. Results of the comparative study for conventional CCS-NMPC: (a) reference of rotor angular speed $\left(\omega_{r}^{*}\right)$ and measured rotor angular speed $\left(\omega_{r}\right) ;(\mathbf{b})$ rotor flux reference $\left(\psi_{r}^{*}\right)$ and rotor flux waveform $\left(\psi_{r}\right)$; (c) $q$-axis stator current waveform. 

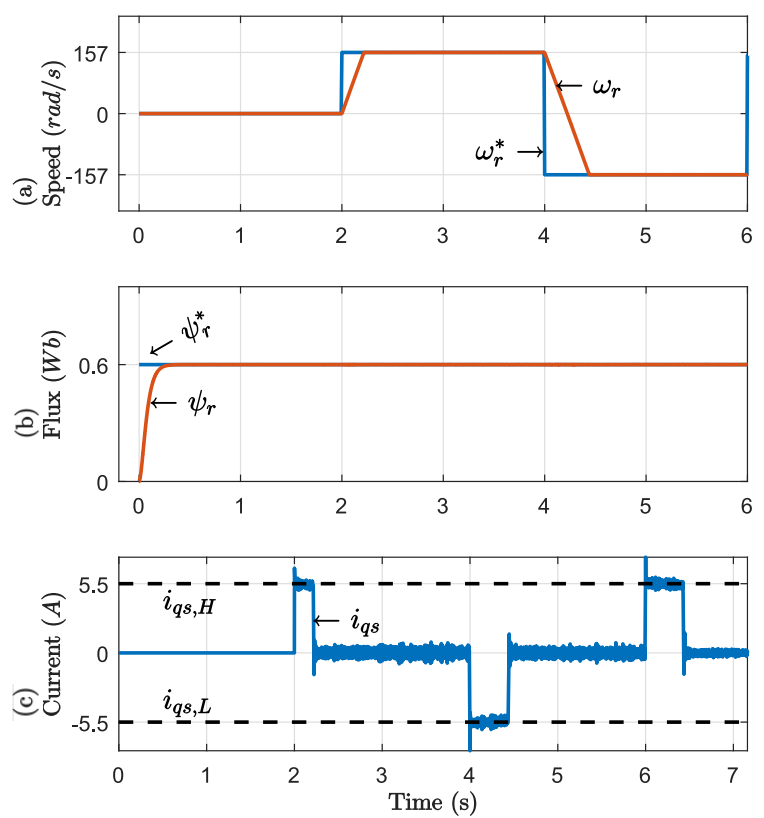

Figure 3. Results of the comparative study for the proposed CCS-NMPC. (a) reference of rotor angular speed $\left(\omega_{r}^{*}\right)$ and measured rotor angular speed $\left(\omega_{r}\right) ;(\mathbf{b})$ rotor flux reference $\left(\psi_{r}^{*}\right)$ and rotor flux waveform $\left(\psi_{r}\right) ;(\mathbf{c}) q$-axis stator current waveform.
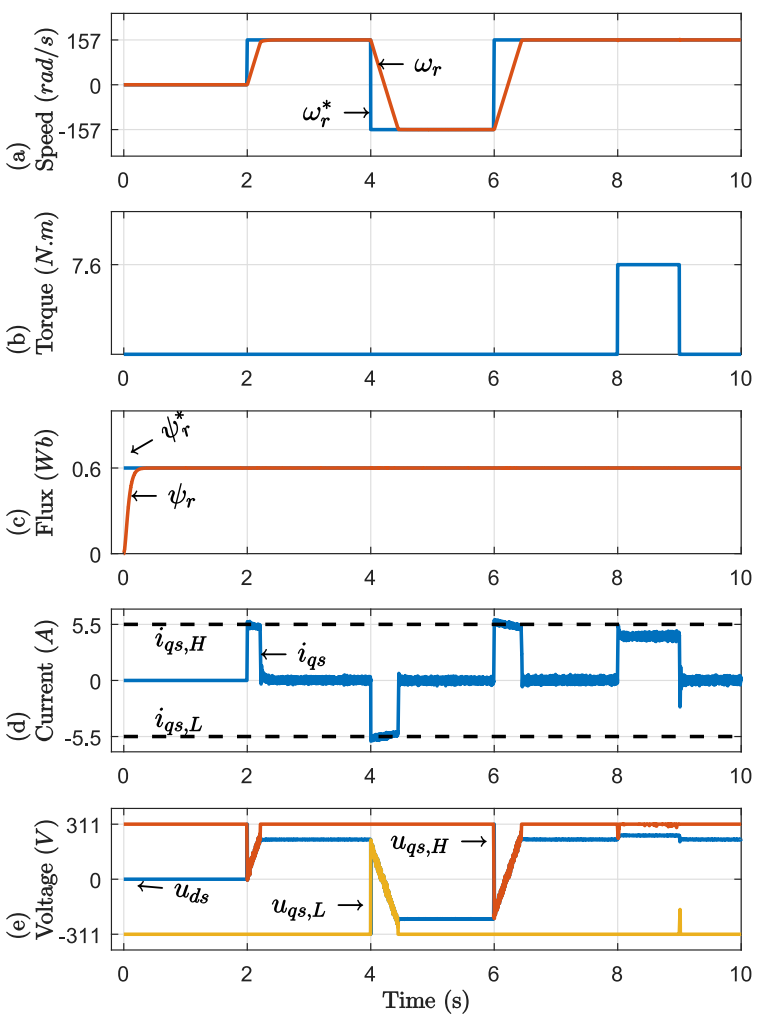

Figure 4. Computer simulation results of a three phase induction motor operating under controlled speed and rotor flux: (a) reference of rotor angular speed $\left(\omega_{r}^{*}\right)$ and measured rotor angular speed $\left(\omega_{r}\right)$; (b) load torque; (c) rotor flux reference $\left(\psi_{r}^{*}\right)$ and rotor flux waveform $\left(\psi_{r}\right)$; (d) $q$-axis stator current waveform; (e) $q$-axis voltage waveform $\left(u_{d s}\right)$ and the boundary values, $\left(u_{d s, L}\right)$ and $\left(u_{d s}, H\right)$. 


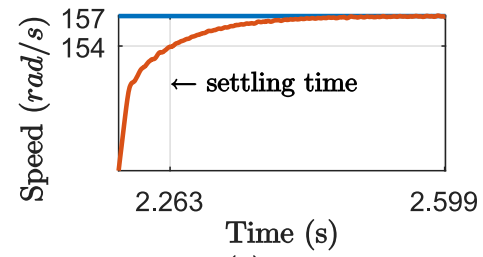

(a)

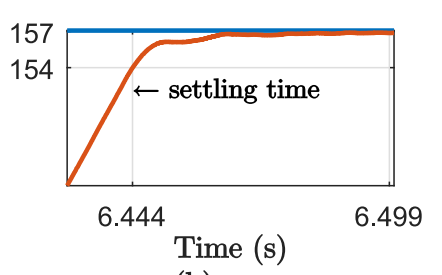

(b)

Figure 5. Details of the simulated speed responses of the proposed CCS-NMPC showing the settling times. (a) For step command $0 \mapsto 157 \mathrm{rad} \mathrm{s}^{-1}$; (b) for step command $-157 \mapsto 157 \mathrm{rad} \mathrm{s}^{-1}$.

\subsection{Experimental Results}

The experimental test bench (Appendix B) consisted of two mechanically-coupled three phase induction motors: one was the motor under test, and the other worked as a load (auxiliary motor); two sets of inverters controlled by a dSPACE processor board, Model DS1104, where the algorithms used were executed; an incremental rotary encoder and voltage and current transducers. The auxiliary motor was fed by a commercial frequency inverter operating in torque control, whose value was set by the dSPACE processor board. The performance, including the robustness of the controller, was investigated under conditions of speed step-variation, torque disturbance, and parameter changes of the motor, as follows.

\subsubsection{Speed Step Response}

The left column of Figure 6 shows the experimental results of the proposed controller. The rotor angular speed response is presented in Figure $6 a$, and in Figure $7 \mathrm{a}$, a zoom is presented to make visible the settling time during the start-up, that is $263 \mathrm{~ms}$. In the case of a reversion command, the settling time was $350 \mathrm{~ms}$, as zoomed in Figure $7 \mathrm{~b}$. Furthermore, its steady-state error was annulled, and no overshoot was observed in the speed response. In turn, the $d$-axis rotor flux followed exactly its reference without any oscillating, according to Figure $6 \mathrm{~b}$.

The efficiency of the proposed approach in restricting the $q$-axis stator current was proven: its value did not surpass the limit of $|5.5 \mathrm{~A}|$ (Figure 6c), i.e., its nominal value. In Figure 6e, it is observed that the $q$-axis stator voltage was saturated, as was expected, since $i_{q s}$ should remain within its limits, i.e., $i_{q s, H}=5.5 \mathrm{~A}$ and $i_{q s, L}=-5.5 \mathrm{~A}$. Note still, in Figure $6 \mathrm{~d}$, that the three phase current envelope analysis showed that the stator current never surpassed its nominal peak value: $6.8 \mathrm{~A}$.

For comparison purposes only, a non-constrained CCS-NMPC was tested, and the results are shown in the right column of Figure 6. It should be noted that the speed dynamic response of the non-constrained CCS-NMPC was worse (Figure $6 \mathrm{f}$ ) than that of our proposed constrained controller, despite the fact that the non-constrained CCS-NMPC employed a second-order filter whose natural frequency was reduced to $250 \mathrm{rad} \mathrm{s}^{-1}$ for keeping $i_{q s}$ between its bound values, unlike our constrained controller, whose natural frequency was $400 \mathrm{rad} \mathrm{s}^{-1}$. Furthermore, as shown in Figure $7 \mathrm{c}, \mathrm{d}$, its settling times during start-up and speed reversion were $650 \mathrm{~ms}$ and $772 \mathrm{~ms}$, respectively. Although the second-order filter smoothed the speed response in the case of the non-constrained controller, $i_{q s}$ surpassed its limit value at the moments of the speed reversion, $t \approx 4 \mathrm{~s}$ and $t \approx 6 \mathrm{~s}$, as shown in Figure $6 \mathrm{~h}$. In short, in the non-constrained case, we had to give up the dynamic performance in an attempt to ensure the safe operation of the drive system. 

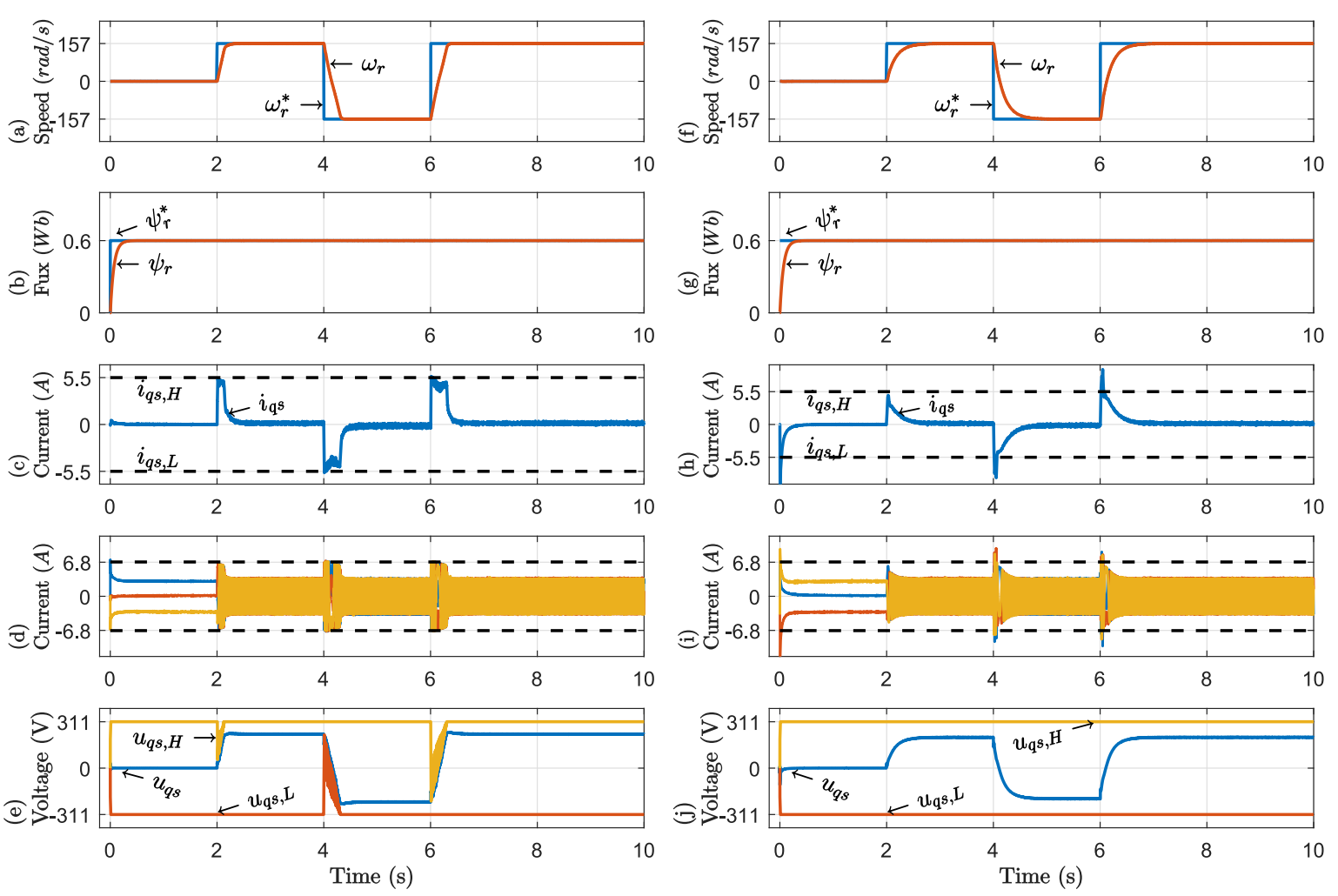

Figure 6. Experimental performance of CCS-NMPC when a speed step-variation occurs: constrained (left column) and non-constrained (right column) cases: (a) and (f) reference of rotor angular speed $\left(\omega_{r}^{*}\right)$ and measured rotor angular speed $\left(\omega_{r}\right) ;(\mathbf{b})$ and $(\mathbf{g})$ rotor flux reference $\left(\psi_{r}^{*}\right)$ and rotor flux waveform $\left(\psi_{r}\right) ;(\mathbf{c})$ and (h) $q$-axis stator current waveform; (d) and (i) three-phase stator current waveform; (e) and (j) $q$-axis voltage waveform $\left(u_{d s}\right)$ and the boundary values, $\left(u_{d s, L}\right)$ and $\left(u_{d s}, H\right)$.

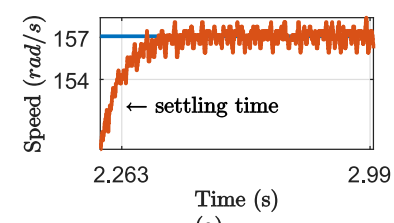

(a)

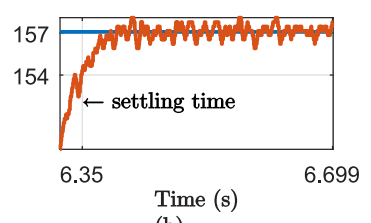

(b)

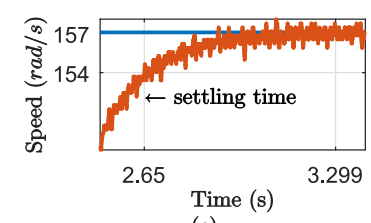

(c)

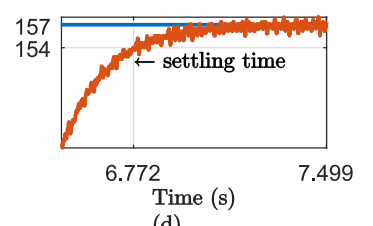

(d)

Figure 7. Details of the settling time of the experimental responses of the controllers for step speed command. (a) Constrained case for step $0 \mapsto 157 \mathrm{rad} \mathrm{s}^{-1}$; (b) constrained case for step $-157 \mapsto$ $157 \mathrm{rad} \mathrm{s}^{-1}$; (c) non-constrained case for step $0 \mapsto 157 \mathrm{rad} \mathrm{s}^{-1}$; (d) non-constrained case for step $-157 \mapsto 157 \mathrm{rad} \mathrm{s}^{-1}$.

\subsubsection{Load Torque Step Response}

With $\psi_{r}=0.6$ Weber, a load torque of 7.6 Newton-meter was applied at the instant 3 with the motor already operating in steady-state. After $5 \mathrm{~s}$, i.e., at the instant $8 \mathrm{~s}$, this load was withdrawn, as shown in Figure $8 \mathrm{~b}$. The speed error caused by the load torque step was rapidly eliminated, as can be seen in Figure 8a, and the rotor flux was kept constant at its commanded value, as shown in Figure 8c. Furthermore, one can note in Figure $8 \mathrm{~d}$ that $i_{q s}$ was suitably limited to its maximum value, i.e., $5.5 \mathrm{~A}$, demonstrating the success of the chosen strategy.

\subsubsection{Low Speed Operation}

Very low speed operation of electric motors is often a problem for model-based predictive control techniques [15]. In such an operation mode, the voltage across the stator phase was close to zero, and the power converter non-linearities (losses, dead time, and others) and inaccuracies of the measurement system (offset, noise, A/D conversion inaccuracies, and others) made the model 
very inaccurate, degrading, therefore, the controller performance. A sinusoidal speed reference with very low amplitude $\left(4 \mathrm{rad} \mathrm{s}^{-1}\right.$ ) was generated by the Root Mean Square Error (RMSE) to evaluate the performance of the proposed controller when the motor operation was at low speeds. The action of the proposed controller resulted in tracking the speed reference, and its measured RMSE value was $0.166 \mathrm{rad} \mathrm{s}^{-1}$, as depicted in Figure 9a. The rotor flux also tracked the reference, and its measured RMSE could be negligible, as shown in Figure 9b. Figure 9c shows the three phase currents of the stator, when the rotor speed inversion occurred. The minimal RMSE values showed the effectiveness of the proposed controller to drive the induction motors when the operation occurred at speeds close to zero.

\subsubsection{Parametric Incompatibility between the Controller and Motor Data}

Discrepancies between declared motor parameters to design the controller and the actual values of the motor could occur. Such parametric incompatibilities could result from errors during the tests for determining the parameter of the motor, or when they change during the motor operation, which may render the operation of the motor unstable. The parameters of the motor under tests were changed over a specific time in the CCS-NMPC algorithm to evaluate the controller robustness against parametric incompatibilities. The instants in the which the parameters had their values changed are shown in Figure 10a. The rotor angular speed response, the rotor flux response, and the behavior of the $q$-axis stator current component are shown in Figure 10b-d, respectively. Initially, the $r_{s}, r_{r}, L_{s}$, and $L_{r}$ parameters were augmented $50 \%$.
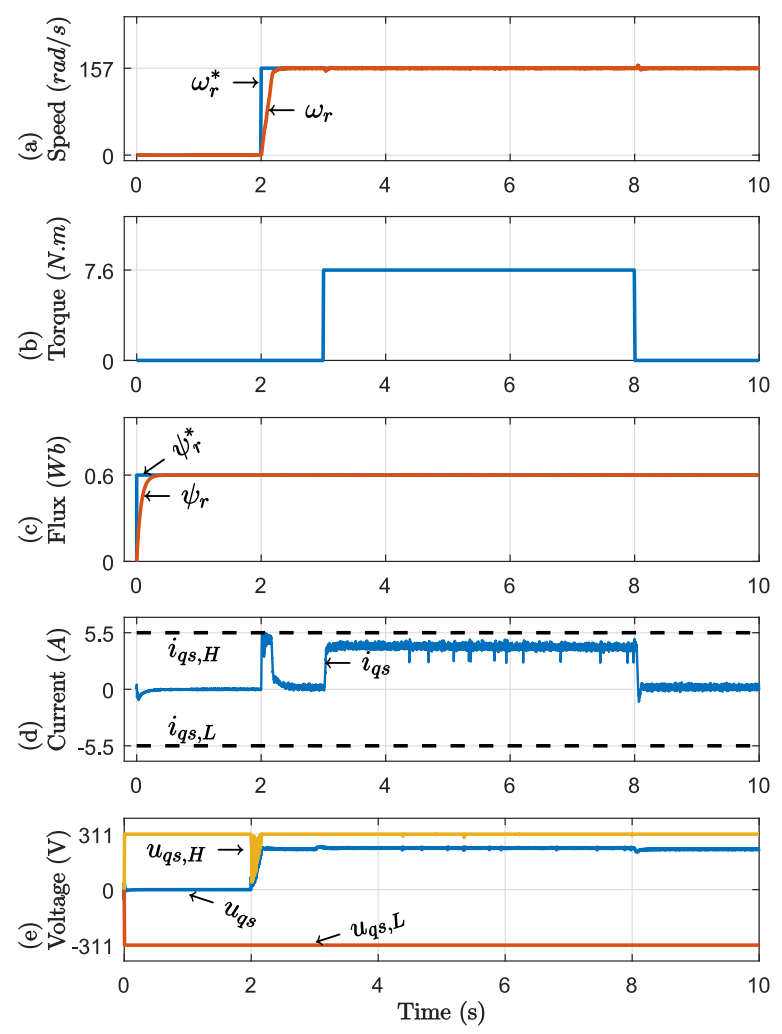

Figure 8. Experimental performance of the proposed CCS-NMPC under load torque step-variation: (a) reference of rotor angular speed $\left(\omega_{r}^{*}\right)$ and measured rotor angular speed $\left(\omega_{r}\right)$; (b) load torque; (c) rotor flux reference $\left(\psi_{r}^{*}\right)$ and rotor flux waveform $\left(\psi_{r}\right)$; (d) $q$-axis stator current waveform; (e) $q$-axis voltage waveform $\left(u_{d s}\right)$ and the boundary values, $\left(u_{d s, L}\right)$ and $\left(u_{d s}, H\right)$. 

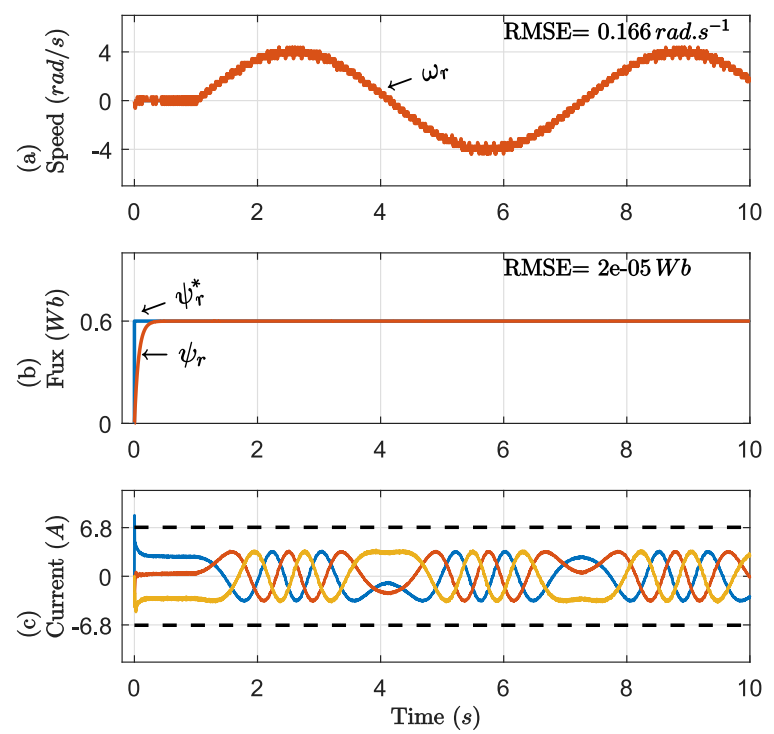

Figure 9. Experimental response of the proposed controller for the very low speed condition: (a) reference of rotor angular speed superposed by measured rotor angular speed $\left(\omega_{r}\right)$; $(\mathbf{b})$ rotor flux reference $\left(\psi_{r}^{*}\right)$ and rotor flux waveform $\left(\psi_{r}\right) ;(\mathbf{c})$ three-phase stator current waveform.
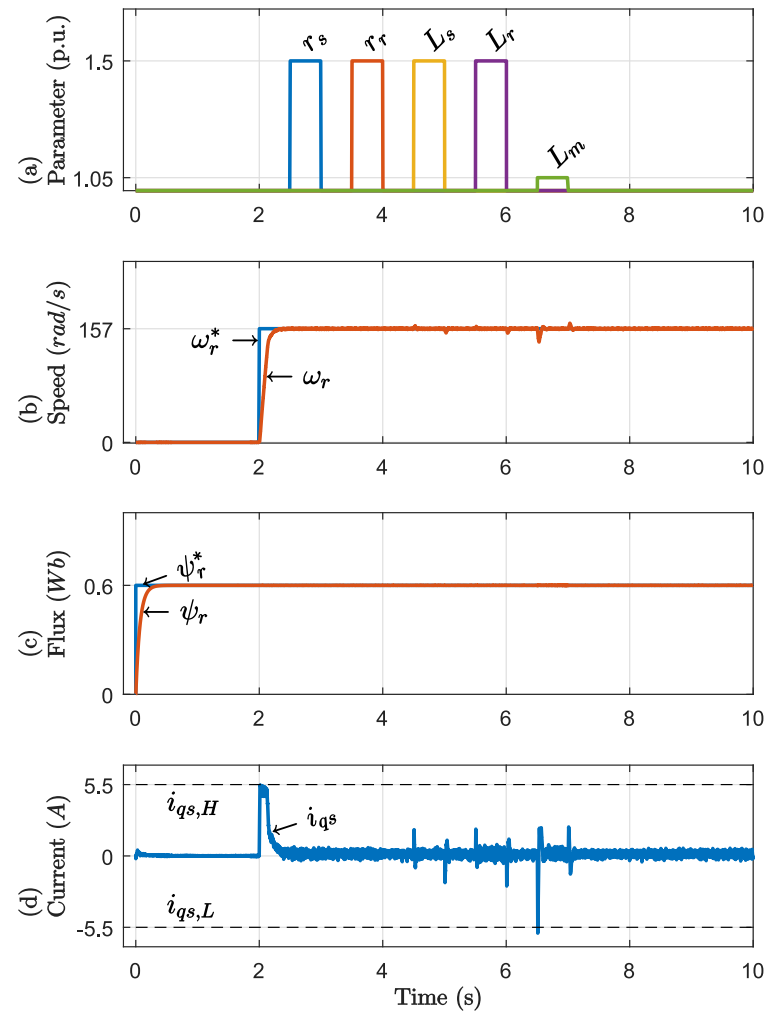

Figure 10. Experimental performance of the proposed CCS-NMPC when motor parameter changes occur: (a) normalized value of motor parameters; (b) reference of rotor angular speed $\left(\omega_{r}^{*}\right)$ and measured rotor angular speed $\left(\omega_{r}\right)$; (c) rotor flux reference $\left(\psi_{r}^{*}\right)$ and rotor flux waveform $\left(\psi_{r}\right) ;(\mathbf{d}) q$-axis stator current waveform.

Analysis of the motor responses showed that variations in rotor and stator resistance did not disturb the system. Moreover, variation in the rotor and stator inductance produced small disturbances in the rotor speed response and consequently in the behavior of the $q$-axis component of the stator current, which were quickly rejected by the control. The primary disturbance was caused when the magnetizing inductance, $L_{m}$, was augmented by $5 \%$; for variations above $5 \%$, the magnitude of the 
motor current exceeded the maximum admissible values by the power converter, requiring, therefore, a protective action. Given that in rotor flux-oriented control, the rotor flux depends directly on the $d$-axis stator current and the magnetizing inductance, it was evident that constant flux control operation resulted in weakening of the rotor flux when the value of the magnetizing inductance considered in the controller was higher than the motor value. In such a case, one expected a higher $q$-axis current to provide power to the motor, whose magnitude could reach very high values. Although the sudden parametric variation considered in this test was the worst case in terms of the controllability of the system, in practical applications, the motor parameters change slowly. For this reason, a more realistic analysis for magnetizing inductance variation was conducted in the next test.

\subsubsection{Sensitivity of Proposed Controller against Magnetizing Inductance}

As already mentioned, it was necessary to check the sensitivity of the proposed controller in a more realistic scenario, i.e., when $L_{m}$ changes slowly. To avoid high values of the $q$-axis current, the $L_{m}$ value was decreased in the controller according to the slope shown in Figure 11a. The main effect observed in the case of the variation of the magnetizing inductance was the $q$-axis current ripples, which increased as much as the parameter discrepancies, as shown in Figure 11d. However, the controller was able to maintain the rotor angular speed (Figure 11b) and the rotor flux (Figure 11c) in their references values. Therefore, these results, along with the previous test, endorsed the robustness of the proposed controller, which remained stable and quickly rejected all disturbances due to parametric variations.
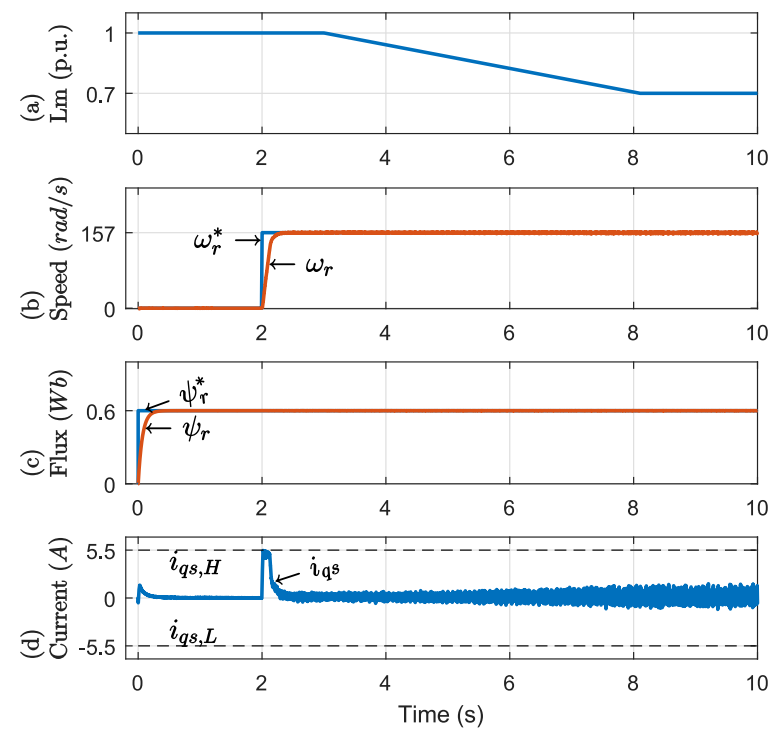

Figure 11. Experimental performance of the proposed CCS-NMPC for smooth variation of $L_{m}$ : (a) normalized value of $L_{m}$; (b) reference of rotor angular speed $\left(\omega_{r}^{*}\right)$ and measured rotor angular speed $\left(\omega_{r}\right) ;(\mathbf{c})$ rotor flux reference $\left(\psi_{r}^{*}\right)$ and rotor flux waveform $\left(\psi_{r}\right)$; (d) $q$-axis stator current waveform.

\section{Conclusions}

This work contributed to the advancement of predictive controllers in the field of electric drives, and the methodology proposed here could be extended to other related areas, such as power generation and electric traction.

Concerning non-modeled disturbances and parameter incompatibilities, the robustness and stability of the system proved to be improved significantly. An anti-windup action was employed, resulting in faster dynamic responses than for a similar, but non-restricted controller. Moreover, the controller proposed in this paper remained stable for fast changes in the speed reference and ensured the safe operation of the drive system. In the face of non-modeled disturbances and parameter incompatibility, the robustness and stability of the system proved to be improved. 
In summary, the aim of this work of improving the transient responses, the robustness, and ensuring the safe operation of the drive system controlled by a non-cascaded CCS-NMPC was achieved with simplicity and low computational load.

Direct power control of wind energy conversion systems and multiphase machines drive are future research related to the proposed controller.

Author Contributions: Conceptualization, F.C.R.; formal analysis, F.C.R. and E.B.; funding acquisition, E.B.; investigation, F.C.R.; methodology, F.C.R. and E.B.; project administration, E.B.; resources, F.C.R.; software, F.C.R.; supervision, E.B.; validation, F.C.R. and E.B.; writing, original draft, F.C.R.; writing, review and editing, F.C.R. and E.B. All authors read and agreed to the published version of the manuscript.

Funding: This research was funded by São Paulo Research Foundation (FAPESP) Grant Number 2017/14068-7.

Conflicts of Interest: The authors declare no conflict of interest. The funders had no role in the design of the study; in the collection, analyses, or interpretation of data; in the writing of the manuscript; nor in the decision to publish the results.

\section{Appendix A. Rated Motor Parameters}

The rated data of the investigated motor connected in $Y$ are shown in Table A1.

Table A1. Rated motor data.

\begin{tabular}{llll}
\hline Data & Value & Parameters & Value \\
\hline Power & $2205 \mathrm{~W}$ & $b$ & $0.002 \mathrm{~N} \mathrm{~m} \mathrm{~s} / \mathrm{rad}$ \\
Line Voltage & $380 \mathrm{~V}$ & $J_{t}$ & $0.00672 \mathrm{~kg} \mathrm{~m}^{2}$ \\
Frequency & $60 \mathrm{~Hz}$ & $r_{s}$ & $2.55 \Omega$ \\
Current & $4.82 \mathrm{~A}$ & $L_{S}$ & $179.24 \mathrm{mH}$ \\
Torque & $12.1 \mathrm{Nm}$ & $r_{r}$ & $1.82 \Omega$ \\
Rotor Flux & $0.69 \mathrm{~Wb}$ & $L_{r}$ & $181.34 \mathrm{mH}$ \\
Speed & $181.7 \mathrm{rad} \mathrm{s}^{-1}$ & $L_{m}$ & $174.04 \mathrm{mH}$ \\
\hline
\end{tabular}

\section{Appendix B. Experimental Test Bench}

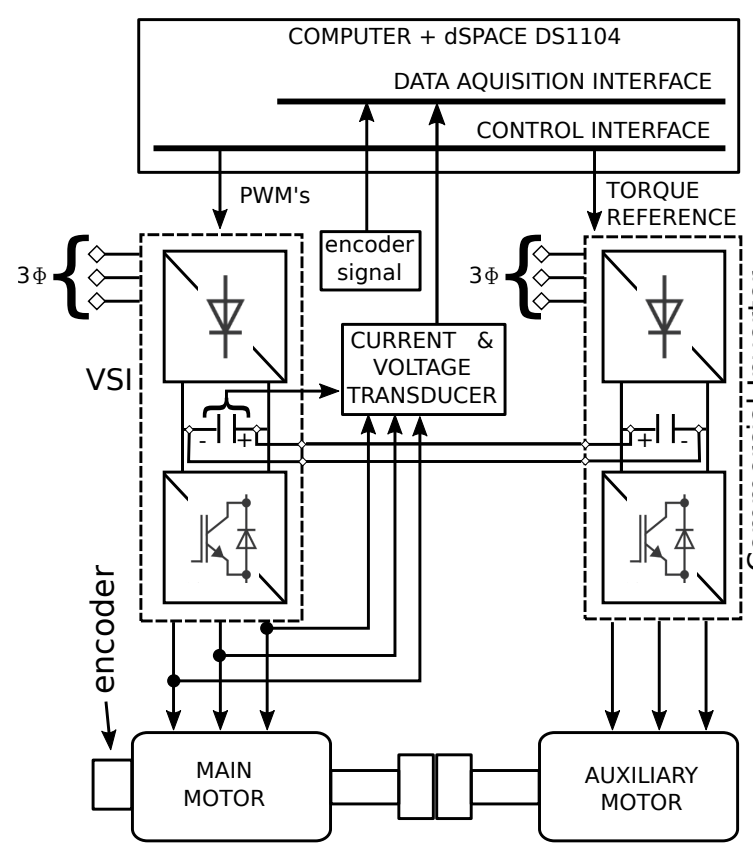

(a) Block scheme

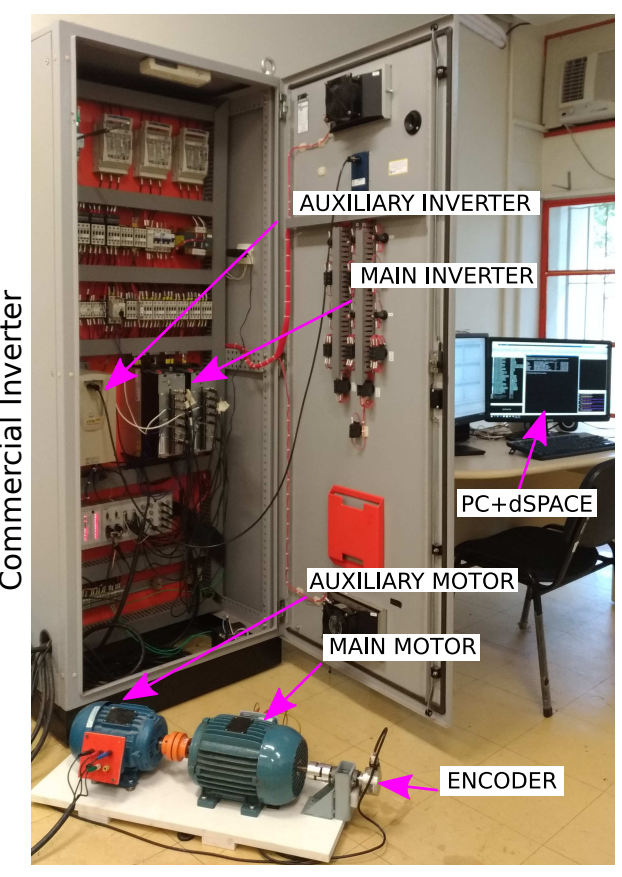

(b) Photo

Figure A1. Experimental test bench. 


\section{References}

1. Alonge, F.; Cirrincione, M.; D'Ippolito, F.; Pucci, M.; Sferlazza, A. Robust Active Disturbance Rejection Control of Induction Motor Systems Based on Additional Sliding Mode Component. IEEE Trans. Ind. Electron. 2017, 64, 5608-5621. [CrossRef]

2. Shao, M.; Deng, Y.; Li, H.; Liu, J.; Fei, Q. Sliding Mode Observer-Based Parameter Identification and Disturbance Compensation for Optimizing the Mode Predictive Control of PMSM. Energies 2019, $12,1857$. [CrossRef]

3. Rosa, F.C.; Lima, F.; Fumagalli, M.A.; Bim, E. Evolving fuzzy controller applied in indirect field oriented control of induction motor. In Proceedings of the 2016 IEEE International Conference on Industrial Technology, Taipei, Taiwan, 14-17 March 2016; pp. 1452-1457.

4. Cirrincione, M.; Accetta, A.; Pucci, M.; Vitale, G. MRAS speed observer for high-performance linear induction motor drives based on linear neural networks. IEEE Trans. Power Electron. 2013, 28, 123-134. [CrossRef]

5. De Marchi, R.A.; Bim, E. A Predictive Direct Power Control reproduced by an Artificial Neural Network controller. In Proceedings of the IECON 2016-42nd Annual Conference of the IEEE Industrial Electronics Society, Florence, Italy, 23-26 October 2016; pp. 1888-1893.

6. De Marchi, R.A.; Dainez, P.S.; Von Zuben, F.J.; Bim, E. A multilayer perceptron controller applied to the direct power control of a doubly fed induction generator. IEEE Trans. Sustain. Energy 2014, 5, 498-506. [CrossRef]

7. Karamanakos, P.; Geyer, T.; Oikonomou, N.; Kieferndorf, F.D.; Manias, S. Direct model predictive control: A review of strategies that achieve long prediction intervals for power electronics. IEEE Ind. Electron. Mag. 2014, 8, 32-43. [CrossRef]

8. De Santana, E.S.; Bim, E.; do Amaral, W.C. A predictive algorithm for controlling speed and rotor flux of induction motor. IEEE Trans. Ind. Electron. 2008, 55, 4398-4407. [CrossRef]

9. Lyu, M.; Wu, G.; Luo, D.; Rong, F.; Huang, S. Robust nonlinear predictive current control techniques for PMSM. Energies 2019, 12, 443. [CrossRef]

10. Norambuena, M.; Garcia, C.; Rodriguez, J. The challenges of predictive control to reach acceptance in the power electronics industry. In Proceedings of the 7th Power Electronics and Drive Systems Technologies Conference, Tehran, Iran, 16-18 February 2016; pp. 636-640.

11. Cortés, P.; Kazmierkowski, M.P.; Kennel, R.M.; Quevedo, D.E.; Rodríguez, J. Predictive control in power electronics and drives. IEEE Trans. Ind. Electron. 2008, 55, 4312-4324. [CrossRef]

12. Rodriguez, J.; Kazmierkowski, M.P.; Espinoza, J.R.; Zanchetta, P.; Abu-Rub, H.; Young, H.A.; Rojas, C.A. State of the art of finite control set model predictive control in power electronics. IEEE Trans. Ind. Inform. 2013, 9, 1003-1016. [CrossRef]

13. Vazquez, S.; Leon, J.I.; Franquelo, L.G.; Rodriguez, J.; Young, H.A.; Marquez, A.; Zanchetta, P. Model predictive control: A review of its applications in power electronics. IEEE Ind. Electron. Mag. 2014, 8, 16-31. [CrossRef]

14. Vazquez, S.; Rodriguez, J.; Rivera, M.; Franquelo, L.G.; Norambuena, M. Model Predictive Control for Power Converters and Drives: Advances and Trends. IEEE Trans. Ind. Electron. 2016, 64, 935-947. [CrossRef]

15. Zhang, Y.; Xia, B.; Yang, H. Performance evaluation of an improved model predictive control with field oriented control as a benchmark. IET Electr. Power Appl. 2017, 11, 677-687. [CrossRef]

16. Preindl, M.; Bolognani, S. Model Predictive Direct Speed Control with Finite Control Set of PMSM Drive Systems. IEEE Trans. Power Electron. 2012, 28, 1007-1015. [CrossRef]

17. Xia, C.; Zhou, Z.; Wang, Z.; Yan, Y.; Shi, T. Computationally efficient multi-step direct predictive torque control for surface-mounted permanent magnet synchronous motor. IET Electr. Power Appl. 2017, 11, 805-814. [CrossRef]

18. Bolognani, S.; Bolognani, S.; Peretti, L.; Zigliotto, M. Design and implementation of model predictive control for electrical motor drives. IEEE Trans. Ind. Electron. 2009, 56, 1925-1936. [CrossRef]

19. Hedjar, R.; Boucher, P.; Dumur, D. Robust nonlinear receding-horizon control of induction motors. Int. J. Electr. Power Energy Syst. 2013, 46, 353-365. [CrossRef]

20. Errouissi, R.; Ouhrouche, M.; Chen, W.H.; Trzynadlowski, A.M. Robust nonlinear predictive controller for permanent-magnet synchronous motors with an optimized cost function. IEEE Trans. Ind. Electron. 2012, 59, 2849-2858. [CrossRef] 
21. Merabet, A. Nonlinear Model Predictive Control for Induction Motor Drive; INTECH Open Access Publisher: London, UK, 2012.

22. Merabet, A.; Ouhrouche, M.; Bui, R.T. Nonlinear predictive control with disturbance observer for induction motor drive. In Proceedings of the 2006 IEEE International Symposium on Industrial Electronics, Montreal, QC, Canada, 9-13 July 2006; Volume 1, pp. 86-91.

23. Errouissi, R.; Ouhrouche, M. Nonlinear predictive controller for a permanent magnet synchronous motor drive. Math. Comput. Simul. 2010, 81, 394-406. [CrossRef]

24. Errouissi, R.; Ouhrouche, M.; Chen, W.H. Robust nonlinear predictive control of a permanent magnet synchronous motor. In Proceedings of the IECON 2012-38th Annual Conference of IEEE Industrial Electronics Society, Montreal, QC, Canada, 25-28 October 2012; pp. 5057-5064.

25. Errouissi, R.; Ouhrouche, M.; Chen, W.H. Robust nonlinear generalized predictive control of a permanent magnet synchronous motor with an anti-windup compensator. In Proceedings of the 2010 IEEE International Symposium on Industrial Electronics (ISIE), Bari, Italy, 4-7 July 2010; pp. 3184-3189.

26. Errouissi, R.; Al-Durra, A.; Muyeen, S.; Leng, S. Continuous-time model predictive control of a permanent magnet synchronous motor drive with disturbance decoupling. IET Electr. Power Appl. 2017, 11, 697-706. [CrossRef]

27. Sawma, J.; Khatounian, F.; Monmasson, E.; Idkhajine, L.; Ghosn, R. Analysis of the impact of online identification on model predictive current control applied to permanent magnet synchronous motors. IET Electr. Power Appl. 2017, 11, 864-873. [CrossRef]

28. Chen, Z.; Qiu, J.; Jin, M. Adaptive finite-control-set model predictive current control for IPMSM drives with inductance variation. IET Electr. Power Appl. 2017, 11, 874-884. [CrossRef]

29. Errouissi, R.; Al-Durra, A.; Muyeen, S.; Leng, S.; Blaabjerg, F. Offset-free Direct Power Control of DFIG Under Continuous-Time Model Predictive Control. IEEE Trans. Power Electron. 2016, 32, 2265-2277. [CrossRef]

30. Tarczewski, T.; Grzesiak, L.M. Constrained state feedback speed control of PMSM based on model predictive approach. IEEE Trans. Ind. Electron. 2016, 63, 3867-3875. [CrossRef]

31. Chen, W.H.; Ballance, D.J.; Gawthrop, P.J.; Gribble, J.J.; O’Reilly, J. Nonlinear PID predictive controller. IEEE Proc. Control Theory Appl. 1999, 146, 603-611. [CrossRef]

32. Slotine, J.J.E.; Li, W. Applied Nonlinear Control; Prentice Hall: Englewood Cliffs, NJ, USA, 1991; Volume 199.

33. Isidori, A. Nonlinear Control Systems; Communications and Control Engineering; Springer: Berlin, Germany, 1995; doi:10.1007/978-1-84628-615-5. [CrossRef]

34. Shin, H.B.; Park, J.G. Anti-windup PID controller with integral state predictor for variable-speed motor drives. IEEE Trans. Ind. Electron. 2012, 59, 1509-1516. [CrossRef]

35. Choi, J.W.; Lee, S.C. Antiwindup strategy for PI-type speed controller. IEEE Trans. Ind. Electron. 2009, 56, 2039-2046. [CrossRef]

(C) 2020 by the authors. Licensee MDPI, Basel, Switzerland. This article is an open access article distributed under the terms and conditions of the Creative Commons Attribution (CC BY) license (http:/ / creativecommons.org/licenses/by/4.0/). 